\title{
Prevalence of allergic diseases and their association with breastfeeding and initiation of complementary feeding in school-age children of Ciudad Guzmán, Mexico
}

\author{
Jaime Morales-Romero, M.D. ${ }^{a}$, Martín Bedolla-Barajas, M.D. ${ }^{b}$, \\ Laura López-Vargas, M.D. ${ }^{c}$, and Enrique Romero-Velarde, M.D. ${ }^{d}$
}

\begin{abstract}
Introduction. The effect that breastfeeding and complementary feeding practices have on the prevalence of allergic diseases has shown inconsistent results.

Objective. To assess the effect of breastfeeding and the initiation of complementary feeding on the prevalence of allergic disease.

Population and Methods. Analytical, crosssectional population-based study conducted in 6-12 year old children attending primary school and selected through a multistage sampling technique. A structured questionnaire was administered to parents or tutors to identify allergic diseases (asthma, allergic rhinitis, or atopic dermatitis), a history of prolonged breastfeeding and age at initiation of complementary feeding. A logistic regression analysis was used to establish associations among variables.

Results. A total of 740 children were included. The frequency of breastfeeding for $\geq 6$ months was $73.4 \%$, and of complementary feeding at $\leq 4$ months old was $31.9 \%$. Prolonged breastfeeding showed no effect on the prevalence of allergic diseases. A protective effect was observed on the frequency of atopic dermatitis when complementary feeding was initiated late, adjusted $\mathrm{OR}=0.36,95 \%$ confidence interval $(\mathrm{CI})$ : $0.1-0.8$ ( $p$ 0.019).

Conclusions. Theprotectiveeffectofbreastfeeding against the prevalence of allergic diseases has not been demonstrated. There is a reduction in the prevalence of atopic dermatitis when complementary feeding is started late.

Key words: breastfeeding, child, asthma, allergic rhinitis, atopic dermatitis.
\end{abstract}

http:/ /dx.doi.org/10.5546/aap.2015.eng.324

\section{INTRODUCTION}

Atopic diseases are a major health problem during childhood, and their prevalence has increased in several regions worldwide. ${ }^{1-4}$ An explanation for this has been searched for among multiple risk factors, including the influence of breastfeeding and the time of initiation of complementary feeding. The assessment of the protective effect of breastfeeding on the development of allergic diseases is not new. In 1936, Grulee and Sanford, documented that breastfeeding had a protective effect against atopic dermatitis; since then, various subsequent investigations have described contradictory results. There is evidence that breastfeeding reduces the frequency of allergic diseases, ${ }^{6}$ but it has also been observed that breastfeeding favors their occurrence, ${ }^{7}$ does not help to prevent atopy and does not provide a transient benefit. ${ }^{9}$

In relation to complementary feeding and its association with allergic diseases, results have pointed out that delaying the introduction of foods to infants does not prevent the development of allergies ${ }^{10,11}$ or allergen sensitization..$^{12}$ A systematic review of this topic showed inconsistent results. ${ }^{13}$

As per our knowledge, there is no published information in Mexico that proves the benefit of breastfeeding or the delay in the introduction of foods to infants and their association with the prevention of allergic diseases. This study is part of a larger epidemiological research conducted in a city located in Western Mexico. Our objective was to assess the effect of breastfeeding and the time of initiation of complementary feeding on the prevalence of allergic diseases in a sample of school-age children.

\section{POPULATION AND METHODS}

Analytical and cross-sectional study; data were collected between April and July of 2008. 


\section{Setting}

Ciudad Guzmán is an urban population located in the south of Jalisco, Mexico. The main economic activities in this region are the delivery of services, industry and agricultural activities.

The methodology used in our study was already described in another published article. ${ }^{14}$ Based on the population, 6-12 year old boys and girls attending private or public primary schools, either the morning or the afternoon shift, were included. The sample size was estimated based on the prevalence of expected asthma in schoolage children (7\%), a 95\% confidence level, and a $2 \%$ accuracy. The sample size was 626 children. Following a $20 \%$ adjustment for potential losses, the final sample size was 752 children.

\section{Sample selection}

The study group was established based on a probabilistic, stratified and three-stage cluster sampling (Figure 1).

\section{Stage 1}

Each school area was considered a stratum, and a sub-sample was estimated for each. In order to establish the number of schools (clusters) to be selected from each stratum, the percentage of students provided by each school area was multiplied by the number of schools in each area, respectively. Schools were selected in a probabilistic fashion.

\section{Stage 2}

At this level, each grade (from first to sixth grade) of selected schools was considered a stratum, while the groups in each grade (e.g., 1A, $1 \mathrm{~B}, 1 \mathrm{C} \ldots$ ) were considered a cluster. At least one group was randomly selected from each stratum.

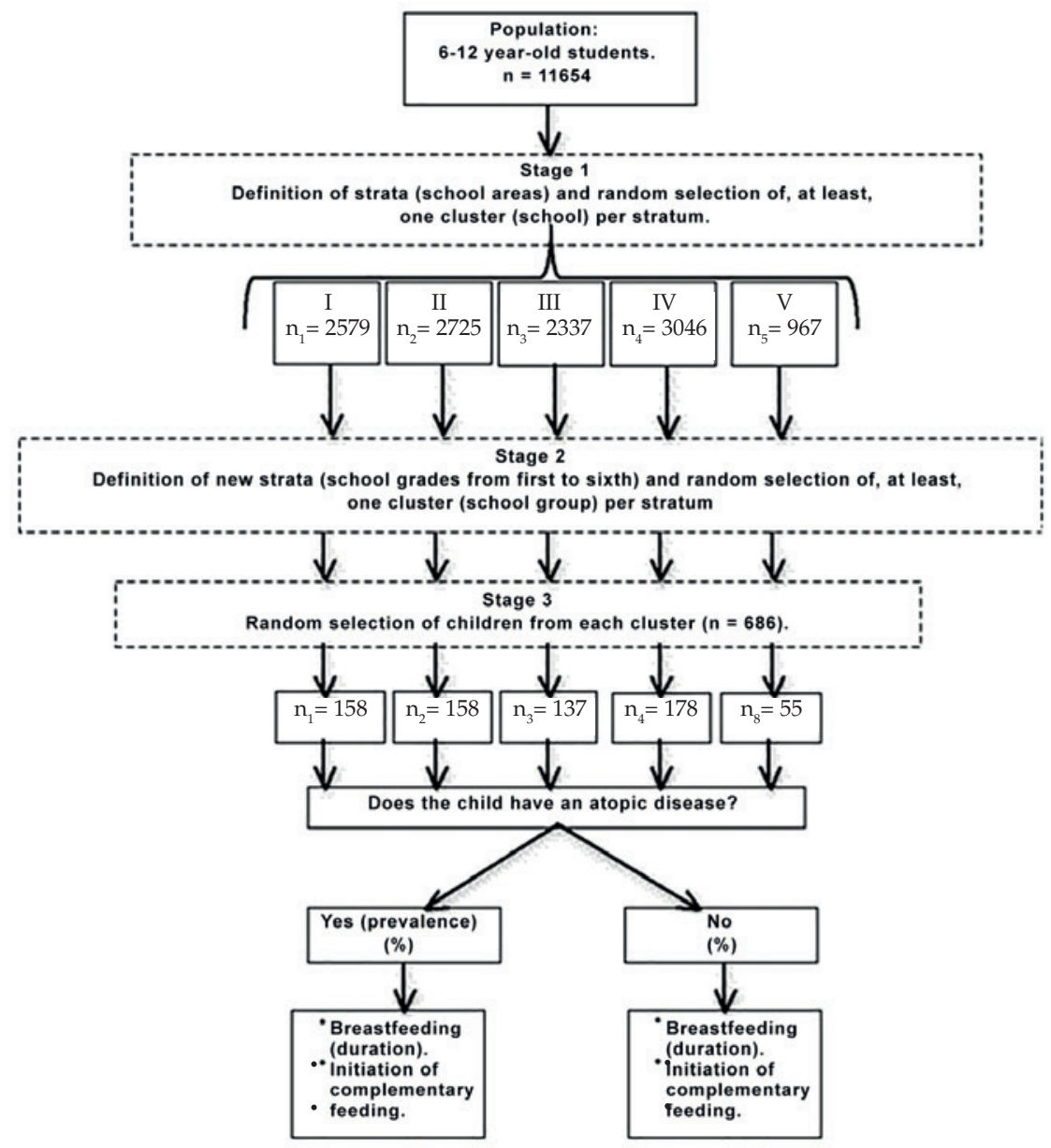




\section{Stage 3}

A list of students' names was obtained for each selected group. Each name was assigned an incremental and unique number for the group and then random numbers were generated in order to complete the sampling. The sample size of each selected school group was established through proportional allocation.

\section{Procedure}

Each school selected in the sampling was visited on a scheduled basis. Once students were selected, their parents were summoned. At a second visit, parents were invited to participate in the study; if they accepted, a structured questionnaire was administered collectively to establish allergic disease prevalence, family history of atopic diseases and eating habits in the first months of life.

\section{Definitions}

The prevalence of asthma, allergic rhinitis and atopic dermatitis was established based on an affirmative answer to the main questions proposed by the International Study of Asthma and Allergies in Childhood (ISAAC): "Has your child ever been diagnosed with asthma?", "Has your child ever been diagnosed with allergic rhinitis?" and "Has your child ever been diagnosed with atopic dermatitis or neurodermatitis or eczema?"

For the purpose of this study, prolonged breastfeeding was defined as breastfeeding that lasted for more than six months, regardless of whether it was exclusive or not; late complementary feeding was defined as the introduction of any solid or liquid food as of four months old.

\section{Statistical analysis}

For the univariate analysis, proportions were compared using the $\chi^{2}$ test (Fisher's exact test or Yates's correction were used if required). Mean values were compared using Student's t test for independent samples, while median values were compared using the Mann-Whitney U test. The association between allergic diseases and breastfeeding and late complementary feeding was assessed using the odds ratio (OR); $95 \%$ confidence intervals were estimated for the OR and proportions. A multivariate analysis was used to adjust risk factors for possible confounding factors (age and sex) with logistic regression. In the model, the dependent variable was the previous diagnosis of allergic disease (yes/no). Separate models were used for asthma, allergic rhinitis and atopic dermatitis. Covariates included in all models were prolonged breastfeeding, late complementary feeding, a combination of both, and a history of maternal allergy. Statistical significance was established based on a $p$ value of $\leq 0.05$. Data were analyzed using the IBM SPSS software, version 20.0 (IBM Co., Armonk, NY, USA) and Statcalc from Epi-Info for Windows.

\section{Ethics}

This study was reviewed and approved by the Ethics and Research Committee of Health Region VI, Secretariat of Health, Ciudad Guzmán, Jalisco, Mexico. In addition, children's parents signed an informed consent form.

\section{RESULTS}

The sample included 740 children, 393 (49.1\%) of them were females. The frequency of mothers who initiated breastfeeding was $94.2 \%$, and the average time of breastfeeding was $10.4 \pm 8.3$ months; breastfeeding prevalence of $\geq 6$ months was $73.4 \%$, and of $\geq 2$ years, $11.9 \%$. Average age at initiation of complementary feeding was $5.7 \pm$ 2.6 months old, and it was started at 4 months old or earlier in $31.9 \%$ of cases.

No significant differences were observed in the rate of mothers who initiated breastfeeding, average time and frequency of prolonged breastfeeding by type of allergic disease (Table 1). The time of initiation of complementary feeding showed a significant association with atopic dermatitis, especially when initiated at $\leq 4$ months old. In relation to the frequency of atopic dermatitis, breastfeeding evidenced a protective effect when it was prolonged and accompanied by late complementary feeding ( $p$ 0.025). This was not documented for asthma and allergic rhinitis.

Using a multivariate logistic regression analysis, Table 2 shows that a history of maternal allergic disease was significantly associated with any of the allergic diseases in children; however, late complementary feeding evidenced a protective effect only in the case of atopic dermatitis.

\section{DISCUSSION}

The prevalence of asthma, allergic rhinitis and atopic dermatitis was $8.1 \%,{ }^{15} 5.5 \%{ }^{14}$ and $3.0 \%,{ }^{16}$ respectively; their behavior has been analyzed before. In Ciudad Guzmán, the frequency of breastfeeding is lower than the national mean 
value ${ }^{17}$ which has also been observed in other large regions of Mexico. Therefore, if there was a risk association between the prevalence of allergic diseases and breastfeeding, an increase in allergic diseases would be expected. However, this does not seem to be the case. Based on data from the Mexican Social Security Institute, one of the most important health agencies in this country, it has been shown that the number of consultations performed to general practitioners, the number of visits to the Emergency Department, and the number of hospital discharges associated with asthma have not increased substantially in a 10-year period..$^{18}$ Findings were similar in a second study, which also evaluated the trend of asthma, allergic rhinitis and atopic dermatitis in Mexican children. ${ }^{19}$ From an epidemiological perspective, and consistent with our results, it seems that there is no association between breastfeeding and the prevention of allergic diseases in Mexico.
The ISAAC study assessed the global prevalence of allergic diseases and factors associated with their occurrence and did not identify breastfeeding as a protective factor against the present development of wheezing, rhinoconjunctivitis, atopic dermatitis or symptoms of severe asthma. ${ }^{20}$

In contrast, a case-control study conducted in 3-7 year-old children with a clinically confirmed diagnosis of asthma, allergic rhinitis and atopic dermatitis reported that exclusive breastfeeding for three or more months acted as a protective factor against atopic diseases. ${ }^{21}$

In our study, it was not possible to document the protective effect of breastfeeding against allergic diseases, but this may be explained by the role of inheritance in their development.

A research conducted in African children reported that, in the absence of a genetic predisposition but with a history of prolonged breastfeeding ( $\geq 6$ months), a protective effect

TABLE 1. History of breastfeeding and complementary feeding initiation in children with allergic diseases*

\begin{tabular}{|c|c|c|c|c|c|c|c|c|c|c|c|c|}
\hline \multirow[b]{2}{*}{ Variable } & \multicolumn{4}{|c|}{ Asthma } & \multicolumn{4}{|c|}{ Allergic rhinitis } & \multicolumn{4}{|c|}{ Atopic dermatitis } \\
\hline & $\begin{array}{c}\text { Yes } \\
(n=60)\end{array}$ & $\begin{array}{c}\text { No } \\
(n=680)\end{array}$ & $\begin{array}{c}\text { OR } \\
(95 \% \mathrm{CI})\end{array}$ & $\mathrm{p}$ & $\begin{array}{c}\text { Yes } \\
(n=41)\end{array}$ & $\begin{array}{c}\text { No } \\
(n=699)\end{array}$ & $\begin{array}{c}\text { OR } \\
(95 \% \mathrm{CI})\end{array}$ & $\mathrm{p}$ & $\begin{array}{c}\text { Yes } \\
(n=22)\end{array}$ & $\begin{array}{c}\text { No } \\
(n=718)\end{array}$ & $\begin{array}{c}\text { OR } \\
(95 \% \mathrm{CI}) \\
\end{array}$ & $\mathrm{p}$ \\
\hline $\begin{array}{l}\text { Age (years), } \\
\text { mean } \pm S D\end{array}$ & $9.6 \pm 1.8$ & $9.4 \pm 1.8$ & --- & 0.41 & $9.1 \pm 1.8$ & $9.5 \pm 1.8$ & ---- & 0.25 & $8.9 \pm 2.1$ & $9.5 \pm 1.8$ & ---- & 0.16 \\
\hline $\begin{array}{l}\text { Female sex, } \\
\text { n (\%) }\end{array}$ & $\begin{array}{c}36 \\
(60.0)\end{array}$ & $\begin{array}{c}357 \\
(52.5)\end{array}$ & $\begin{array}{c}1.4 \\
(0.8-2.4)\end{array}$ & 0.26 & $\begin{array}{c}24 \\
(58.5)\end{array}$ & $\begin{array}{c}369 \\
(52.8)\end{array}$ & $\begin{array}{c}1.3 \\
(0.70-2.4)\end{array}$ & 0.47 & $\begin{array}{c}11 \\
(50.0)\end{array}$ & $\begin{array}{c}382 \\
(53.2)\end{array}$ & $\begin{array}{c}0.9 \\
(0.4-2.1)\end{array}$ & 0.77 \\
\hline $\begin{array}{l}\text { Breastfeeding } \\
\text { (yes), n (\%) }\end{array}$ & $\begin{array}{c}55 \\
(93.2)\end{array}$ & $\begin{array}{c}638 \\
(94.2)\end{array}$ & $\begin{array}{c}0.84 \\
(0.3-2.4)\end{array}$ & 0.77 & $\begin{array}{c}37 \\
(90.2)\end{array}$ & $\begin{array}{c}656 \\
(94.4)\end{array}$ & $\begin{array}{c}0.6 \\
(0.2-1.6)\end{array}$ & 0.29 & $\begin{array}{c}21 \\
(96.0)\end{array}$ & $\begin{array}{c}672 \\
(94.0)\end{array}$ & $\begin{array}{c}1.3 \\
(0.2-10.0)\end{array}$ & 0.99 \\
\hline $\begin{array}{l}\text { Breastfeeding } \\
\text { (months), } \\
\text { median } \\
\text { (lower limit - } \\
\text { upper limit) }\end{array}$ & $\begin{array}{c}8 \\
(0-36)\end{array}$ & $\begin{array}{c}8 \\
(0-48)\end{array}$ & ---- & 0.31 & $\begin{array}{c}6 \\
(0-36)\end{array}$ & $\begin{array}{c}8 \\
(0-48)\end{array}$ & --- & 0.48 & $\begin{array}{c}7 \\
(0-36)\end{array}$ & $\begin{array}{c}8 \\
(0-48)\end{array}$ & ---- & 0.11 \\
\hline $\begin{array}{l}\text { Age at initiation of } \\
\text { complementary } \\
\text { feeding (months), } \\
\text { median } \\
\text { (lower limit - } \\
\text { upper limit) }\end{array}$ & $\begin{array}{c}6 \\
(1-12)\end{array}$ & $\begin{array}{c}6 \\
(1-24)\end{array}$ & --- & 0.53 & $\begin{array}{c}6 \\
(2-15)\end{array}$ & $\begin{array}{c}6 \\
(1-24)\end{array}$ & --- & 0.15 & $\begin{array}{c}4 \\
(1-6)\end{array}$ & $\begin{array}{c}6 \\
(1-24)\end{array}$ & --- & 0.001 \\
\hline $\begin{array}{l}\text { Complementary } \\
\text { feeding } \\
\leq 4 \text { months old, } \mathrm{n}(\%)\end{array}$ & $\begin{array}{c}22 \\
(37.3)\end{array}$ & $\begin{array}{c}213 \\
(31.5)\end{array}$ & $\begin{array}{c}1.3 \\
(0.7-2.3)\end{array}$ & 0.36 & $\begin{array}{c}11 \\
(26.8)\end{array}$ & $\begin{array}{c}224 \\
(32.2)\end{array}$ & $\begin{array}{c}0.8 \\
(0.4-1.6)\end{array}$ & 0.47 & $\begin{array}{c}12 \\
(54.5)\end{array}$ & $\begin{array}{c}223 \\
(31.2)\end{array}$ & $\begin{array}{c}2.6 \\
(1.1-6.7)\end{array}$ & 0.02 \\
\hline $\begin{array}{l}\text { Prolonged } \\
\text { breastfeeding and } \\
\text { late complementary } \\
\text { feeding, }+\mathrm{n}(\%)\end{array}$ & $\begin{array}{c}24 \\
(40.7)\end{array}$ & $\begin{array}{c}349 \\
(51.6)\end{array}$ & $\begin{array}{c}0.6 \\
(0.4-1.1)\end{array}$ & 0.11 & $\begin{array}{c}23 \\
(56.1)\end{array}$ & $\begin{array}{c}350 \\
(50.4)\end{array}$ & $\begin{array}{c}1.3 \\
(0.6-2.5)\end{array}$ & 0.48 & $\begin{array}{c}6 \\
(27.3)\end{array}$ & $\begin{array}{c}367 \\
(51.5)\end{array}$ & $\begin{array}{c}0.35 \\
(0.1-0.9)\end{array}$ & 0.025 \\
\hline
\end{tabular}

* Allergic disease: asthma, allergic rhinitis, atopic dermatitis.

Proportions were compared using the $\chi^{2}$ test or Fisher's exact test or Yates' correction, if required.

Mean values were compared using Student's t test. Median values were compared using the Mann-Whitney U test.

† Prolonged breastfeeding: $\geq 6$ months. Late complementary feeding: $>4$ months old. 
against the development of allergic diseases was recorded. 22

Likewise, a cohort study showed that, at 44 years old, it was the history of maternal allergic disease, and not exclusive breastfeeding, that favored the possibility of developing asthma, allergic rhinitis, food allergy or allergic sensitization. ${ }^{23}$ A multidisciplinary review aimed at assessing the impact of early feeding on the occurrence of allergic diseases concluded that breastfeeding seemed to offer a protective effect against atopic disease, and such result appeared to be stronger in children with inherited atopy. ${ }^{24}$ Our findings support the role of inheritance in the origin of allergic diseases since the three analyzed models showed that a history of maternal allergy remained as a factor associated with their development. As per our considerations, this is one of the main reasons why breastfeeding does not appear to help with their prevention.

An additional explanation for why breastfeeding does not appear to be protective may be related to the time of initiation and the type of complementary feeding. Specifically in relation to atopic dermatitis, we observed that introducing foods as of 4 months old remained as a protective factor, regardless of breastfeeding. This suggests that the intestinal immune system plays a significant role in regulating mechanisms of allergen tolerance, which are initially foodrelated; this way, the development of allergic diseases would be modified. It has been observed that children who eat fish at least twice a week during their first year of life have a lower risk of developing allergic diseases and allergic sensitization at 4 years old ${ }^{25}$ This is also the case of foods like wheat, rice, oatmeal, barley or eggs, which if consumed earlier than the time recommended for their introduction appear to reduce the risk of asthma, allergic rhinitis, and atopic sensitization. ${ }^{26}$

More recently, it has been shown that, in children with atopic dermatitis, the early introduction of peanut reduced the frequency of peanut allergy. ${ }^{27}$ Thus, there is a wide range of possibilities to modulate the immune response through food introduction. Our research did not enable a profound analysis of the procedure of introducing different foods to children's diet since we only inquired about the age at initiation of

TABLE 2. Association of prolonged breastfeeding accompanied by complementary feeding with allergic diseases

\begin{tabular}{|c|c|c|c|c|c|c|}
\hline & \multicolumn{3}{|c|}{ Non-adjusted model } & \multicolumn{3}{|c|}{ Adjusted model* } \\
\hline & OR & $95 \% \mathrm{CI}$ & $\mathbf{p}$ & OR & $95 \% \mathrm{CI}$ & $\mathrm{p}$ \\
\hline \multicolumn{7}{|l|}{ Dependent variable: asthma } \\
\hline Age & 1.1 & $0.9-1.2$ & 0.40 & --- & --- & 0.43 \\
\hline Female sex & 1.5 & $0.8-2.5$ & 0.17 & --- & --- & 0.17 \\
\hline Prolonged breastfeeding & 0.9 & $0.3-2.1$ & 0.71 & --- & --- & 0.35 \\
\hline Late complementary feeding & 1.0 & $0.4-2.4$ & 0.94 & --- & --- & 0.49 \\
\hline \multicolumn{7}{|l|}{ Prolonged breastfeeding + } \\
\hline late complementary feeding & 0.7 & $0.2-2.1$ & 0.53 & --- & --- & 0.20 \\
\hline Allergic mother & 2.2 & $1.1-4.1$ & 0.02 & 2.1 & $1.1-4.0$ & 0.017 \\
\hline \multicolumn{7}{|l|}{ Dependent variable: allergic rhinitis } \\
\hline Age & 0.9 & $0.1-1.1$ & 0.35 & --- & --- & 0.32 \\
\hline Female sex & 1.5 & $0.7-3.0$ & 0.24 & --- & --- & 0.22 \\
\hline Prolonged breastfeeding & 0.6 & $0.2-2.3$ & 0.51 & --- & --- & 0.88 \\
\hline Late complementary feeding & 0.9 & $0.2-3.0$ & 0.81 & --- & --- & 0.60 \\
\hline \multicolumn{7}{|l|}{ Prolonged breastfeeding + } \\
\hline late complementary feeding & 1.7 & $0.4-7.8$ & 0.52 & --- & --- & 0.60 \\
\hline Allergic mother & 2.9 & $1.4-6.1$ & 0.004 & 2.9 & $1.4-5.9$ & 0.004 \\
\hline \multicolumn{7}{|c|}{ Dependent variable: atopic dermatitis } \\
\hline Age & 0.8 & $0.7-1.1$ & 0.21 & --- & --- & 0.20 \\
\hline Female sex & 0.9 & $0.4-2.3$ & 0.97 & --- & --- & 0.97 \\
\hline Prolonged breastfeeding & 0.9 & $0.3-3.3$ & 0.94 & --- & --- & 0.49 \\
\hline Late complementary feeding & 0.5 & $0.1-2.1$ & 0.37 & 0.36 & $0.1-0.8$ & 0.019 \\
\hline \multicolumn{7}{|l|}{ Prolonged breastfeeding + } \\
\hline late complementary feeding & 0.59 & $0.1-3.4$ & 0.56 & --- & --- & 0.39 \\
\hline Allergic mother & 2.7 & $1.1-6.9$ & 0.04 & 2.8 & $1.1-7.1$ & 0.03 \\
\hline
\end{tabular}

OR: odds ratio obtained through logistic regression.

* The OR of variables used for adjustment is not shown. 
food introduction. Therefore, caution should be exercised when interpreting our results.

In addition, the type of foods consumed during breastfeeding and the microorganisms associated with their use also contribute to the development of allergic diseases. A cohort study showed that up to one third of children who were exclusively or partially breast-fed had Lactobacillus in their saliva; in contrast, none of the formula-fed infants showed this type of bacteria. ${ }^{28}$

This also occurred with nasopharyngeal microorganisms. Infants on exclusive breastfeeding had a higher level of Dolosigranulum and Corynebacterium, and a lower level of Staphylococcus and anaerobic bacteria such as Prevotella and Veillonella, when compared to exclusively formula-fed infants. ${ }^{29}$

When assessing gut microbiota through the detection of fecal bacteria, a study conducted in different European countries documented that bifidobacteria predominated among breastfed infants, while a high proportion of Bacteroides and Clostridium was observed in formula-fed infants. ${ }^{30}$ Such differences in gut microbiota, which are caused by the type of feeding, suggest that there are immune-response modulation mechanisms that may help to prevent allergic diseases.

\section{Limitations}

A limitation of our study is that the diagnosis of allergic diseases could not be verified. Instead, such diagnosis was established using the most important questions from the ISAAC questionnaires, which have proven to be highly consistent as per their epidemiological assessment. ${ }^{20}$ Another limitation was the problem to establish an accurate proportion of mothers who used breastfeeding as the single source of food for their children, which would have allowed us to analyze the role of breastfeeding on the prevalence of allergic diseases. In addition, potential confounding variables, such as exposure to cigarette smoke and environmental pollution, were not measured.

In terms of methodology, and as a result of our study's retrospective design, there is a possibility of a recall bias given that parents of allergic children tend to recall more details in relation to their children's feeding. Besides, the sample size was not expressly calculated to estimate the difference between allergic diseases in the children of allergic mothers with different feeding patterns. In the light of the preceding limitations, our results should be used with caution.
By contrast, the strengths of our study in terms of methodology include an adequate sample size, that allowed to estimate the prevalence of allergic diseases, and a strict sampling, which was performed in a probabilistic, stratified and clustered manner. The sampling frame was the entire student population of Ciudad Guzmán.

\section{CONCLUSIONS}

Although breastfeeding is recognized by its nutritional properties, its significant role in the protection against infectious diseases, and for favoring the development of an emotional bond between the mother and newborn dyad, it has not proven to be related to the prevalence of allergic diseases in school-age children. However, initiating complementary feeding as of 4 months old did show an association with a reduction in the prevalence of atopic dermatitis.

\section{REFERENCES}

1. Cooper PJ, Rodrígues LC, Cruz AA, Barreto ML. Asthma in Latin America: a public heath challenge and research opportunity. Allergy 2009;64(1):5-17.

2. Aït-Khaled N, Pearce N, Anderson HR, Ellwood P, et al. Global map of the prevalence symptoms of rhinoconjunctivitis in children: The International Study of Asthma and Allergies in Childhood (ISAAC) Phase Three. Allergy 2009;64(1):123-48.

3. Arnedo-Pena A, García-Marcos L, García-Hernández G, Aguinagua-Ontoso I, etal. Tendencia temporal y variaciones geográficas de la prevalencia de síntomas de rinitis alérgica en escolares de 6-7 años de ocho áreas españolas, según el ISAAC. An Pediatr (Barc) 2005;62(3):229-36.

4. Gupta R, Sheikh A, Strachan DP,Anderson HR. Time trends in allergic disorders in the UK. Thorax 2007;62(1):91-6.

5. GruleeCG,Sanford HN. The influence of breast and artificial feeding on infantile eczema. J Pediatr 1936;9(2):223-5.

6. Kull I,Wickman M, Lilja G, NordvallSL, et al. Breastfeeding and allergic diseases in infants - a prospective birth cohort study. Arch Dis Child 2002;87(6):478-81.

7. Takemura Y, Sakurai Y, Honjo S, Kusakari S, et al. Relation between breastfeeding and the prevalence of asthma: the Tokorozawa Childhood Asthma and Pollinosis Study. Am J Epidemiol 2001;154(2):115-9.

8. Savilahti E, Tainio VM, Salmenperä L, Siimes MA, et al. Prolonged exclusive breast feeding and heredity as determinants in infantile atopy. Arch Dis Child 1987;62(3):269-73.

9. Matheson MC, Erbas B, Balasuriya A, Jenkins MA, et al. Breast-feeding and atopic disease: a cohort study from childhood to middle age. J Allergy Clin Immunol 2007;120(5):1051-7.

10. Zutavern A, Von Mutius E, Harris J, Mills P, et al. The introduction of solids in relation to asthma and eczema. Arch Dis Child 2004;89(4):303-8.

11. Zutavern A, Brockow I, Schaaf B, Von Berg A, et al. Timing of solid food introduction in relation to eczema, asthma, allergic rhinitis, and food and inhalant sensitization at the age of 6 years: results from the prospective birth cohort study LISA. Pediatrics 2008;121(1):e44-52.

12. Nwaru BI, Erkkola M, Ahonen S, Kaila M, et al. Age at the 
introduction of solid foods during the first year and allergic sensitization at age 5 years. Pediatrics 2010;125(1):50-9.

13. Tarini BA, Carroll AE, Sox CM, Christakis DA. Systematic review of the relationship between early introduction of solid foods to infants and the development of allergic disease. Arch Pediatr Adolesc Med 2006;160(5):502-7.

14. Bedolla-Barajas M, Cuevas-Ríos G, García-Barboza E, Barrera-Zepeda AT, et al. Prevalencia y factores asociado a la rinitis alérgica en escolares de ciudad Guzmán, México. Rev Invest Clin 2010;62(3):244-51.

15. Bedolla-Barajas M, Barrera-Zepeda AT, López-Zaldo JB, Morales-RomeroJ. Asthma in Mexican school-age children is not associated with passive smoking or obesity. Asia Pac Allergy 2013;3(1):42-9.

16. Bedolla-Barajas M, Barrera-Zepeda AT, Morales-RomeroJ. Dermatitis atópica en niños escolares de Ciudad Guzmán, México. Prevalencia y factores asociados. Rev Alerg Mex 2010;57(3):71-8

17. Gutiérrez JP, Rivera-Dommarco J, Shamah-Levy T, Villalpando-HernándezS, etal.Encuesta Nacional deSalud y Nutrición 2012. Resultados Nacionales. Cuernavaca: Instituto Nacional de Salud Pública;2012. [Accessed on: March 9, 2015]. Available at: http://ensanut.insp.mx/ informes/ENSANUT2012ResultadosNacionales.pdf.

18. Vargas MH, Díaz-Mejía GS, Furuya ME, Salas J, et al. Trends of asthma in Mexico: an 11-year analysis in a nationwide institution. Chest 2004;125(6):1993-7.

19. Barraza-VillarrealA,Hernández-Cadena L,Moreno-Macías $\mathrm{H}$, Ramírez-Aguilar M, et al. Trends in the prevalence of asthma and other allergic diseases in schoolchildren from Cuernavaca, Mexico. Allergy Asthma Proc 2007;28(3):368-74.

20. Björkstén B, Aït-Khaled N, Innes Asher M, Clayton TO, et al. Global analysis of breast feeding and risk of symptoms of asthma, rhinoconjunctivitis and eczema in 6-7 year old children: ISAAC Phase Three. Allergol Immunopathol (Madr) 2011;39(6):318-25.
21. Acevedo Villafañe C, Latorre Latorre F, Cifuentes Cifuentes L, Díaz-Martínez LA, etal. Influencia dela lactancia materna y la alimentación en el desarrollo de alergias en los niños. Aten Primaria 2009;41(12):675-80.

22. Obihara CC, Marais BJ, Gie RP, Potter P, et al. The association of prolonged breastfeeding and allergic disease in poor urban children. Eur Respir J 2005;25(6):970-7.

23. Matheson MC, Erbas B, Balasuriya A, Jenkins MA, et al. Breast-feeding and atopic disease: a cohort study from childhood to middle age. J Allergy Clin Immunol 2007;120(5):1051-7.

24. Van Odijk J, Kull I, Borres MP, Brandtzaeg P, et al. Breastfeeding and allergic disease: a multidisciplinary review of the literature (1966-2001) on the mode of early feeding in infancy and its impact on later atopic manifestations. Allergy 2003;58(9):833-43.

25. Kull I, Bergström A, Lilja G, Pershagen G, et al. Fish consumption during the first year of life and development of allergic diseases during childhood. Allergy 2006;61(8):1009-15.

26. Nwaru BI, Takkinen HM, Niemelä O, Kaila M, etal. Timing of infant feeding in relation to childhood asthma and allergic diseases. J Allergy Clin Immunol 2013;131(1):78-86.

27. Du Toit G, Roberts G, Sayre PH, Bahnson HT, et al. Randomized trial of peanut consumption in infants at risk for peanut allergy. N Engl J Med 2015;372(9):803-13.

28. Holgerson PL, Vestman NR, Claesson R, Ohman C, et al. Oral microbial profile discriminates breast-fed from formula- fed infants. J Pediatr Gastroenterol Nutr 2013;56(2):127-36.

29. Biesbroek G, Bosch AA, Wang X, Keijser BJ, et al. The impact of breastfeeding on nasopharyngeal microbial communities in infants. Am J Respir Crit Care Med 2014;190(3):298-308.

30. Fallani M, Young D, Scott J, Norin E, et al. Intestinal microbiota of 6-week-old infants across Europe: geographic influence beyond delivery mode, breastfeeding, and antibiotics. J Pediatr Gastroenterol Nutr 2010;51(1):77-84. 